\title{
THE PREVALENCE OF INJURIES AND ITS ASSOCIATION WITH THE CHARACTERISTICS OF TRAINING IN AMERICAN FOOTBALL PLAYERS IN BRAZIL
}

original paper

( ) University School of Physical Education in Wroclaw

DOI: https://doi.org/10.5114/hm.2019.79041

\section{FILIPE ESTACIO COSTA ${ }^{1}$, JULIANO DAL PUPO ${ }^{1}$, JONATHAN BARTH ${ }^{1}$, EWERTTON DE SOUZA BEZERRA ${ }^{1,2}$, AMADEO FELIX SALVADOR ${ }^{3}$}

${ }^{1}$ Federal University of Santa Catarina, Florianópolis, Brazil

${ }^{2}$ Federal University of Amazonas, Manaus, Brazil

${ }^{3}$ University of Illinois at Urbana-Champaign, Champaign, United States

\section{ABSTRACT}

American football is a high-impact collision sport, which may lead to high injury rates in the players. Thus, knowing the aetiology and incidence of injuries may be useful not only for the treatment, but especially to help sports professionals to develop strategies or mechanisms of prevention while aiming to maintain the physical integrity of the athletes.

Purpose. The aim of the study was to verify the prevalence of injury among American football players from the Santa Catarina state of Brazil.

Methods. The total of 140 athletes were evaluated in the study with the use of an online questionnaire. Descriptive logistic regression and t-test analysis were applied $(p<0.05)$.

Results. A high injury prevalence (74\%) in the evaluated athletes was observed. Most of these injuries occurred during training (56\%) and by direct contact between players (64\%). Shoulders, knees, and hand/fingers were the most commonly injured body parts $(14 \%, 13 \%, 12 \%$, respectively). The most frequent types of injuries were those related to joints (46\%) and muscles (39\%), and very few concussions were reported. We found a significant positive association showing that the athletes that performed a conditioning program presented higher injury prevalence $(p=0.01)$.

Conclusions. American football players of the Santa Catarina state are affected by high injury prevalence. The training characteristics, in general, do not seem to be associated with injury prevalence. Thus, aiming to reduce the exposure to injuries, we recommend for coaches and trainers to monitor the total volume of training and participation in matches.

Key words: physical education and training, athletic injuries, musculoskeletal system, epidemiology

\section{Introduction}

American football is a very popular sport in the United States of America, with notable growth around the world [1, 2]. In Brazil, it has been developing for the last few years and the number of players has significantly increased, but most athletes are considered amateurs. Currently, Brazil has more than 130 affiliated American football teams [3]. In this discipline, the object of the match is to conquer territory, progressing in the opponent's field, aiming to score a touchdown (maximum score) [4]. The match is divided into 4 quar- ters of 12 minutes each, with an interval of 15 minutes between the second and third quarters, and it is played with 11 players for each team. The match is composed of intermittent and acyclic actions performed in high intensity [5]. In this context, the anaerobic metabolism and physical capacities related to strength and power are preponderant in decisive actions of the sport [6].

One important characteristic of American football is the high-impact collisions, which are almost unavoidable and occur mainly during tackles (i.e., acts of physically stopping the opponent who possesses the

Correspondence address: Filipe Estácio Costa, Department of Physical Education, Universidade Federal de Santa Catarina (UFSC), Campus Reitor João David Ferreira Lima, s/n - Trindade, Florianópolis - SC, Brazil, 88040-900,

e-mail: lipeestacio@gmail.com

Received: May 7, 2018

Accepted for publication: September 27, 2018

Citation: Costa FE, Dal Pupo J, Barth J, Bezerra ES, Salvador AF. The prevalence of injuries and its association with the characteristics of training in American football players in Brazil. Hum Mov. 2019;20(1):31-37; doi: https://doi.org/10.5114/ hm.2019.79041. 
F.E. Costa, J. Dal Pupo, J. Barth, E.S. Bezerra, A.F. Salvador, Injury prevalence in American football

ball, taking him to the ground) and blocks. Therefore, athletes are exposed to an elevated injury risk due to impact in matches or training. To prevent injuries, all athletes have to wear protective gear like helmets, shoulder pads, mouthguards, and other items [7].

In view of these characteristics, several scholars have been studying injuries in American football [7-19]. The generality of the studies revealed that the mechanism of injury was predominantly by direct contact between players [18, 19]. Usually, injury rates are bigger in matches than in training; however, considering that athletes spend more time training than playing official matches, the absolute number of injuries in training tends to be higher than that in matches $[12,18]$. In addition, 2 studies with college athletes (Japanese and Americans) showed that more than $50 \%$ of all injuries occurred in the lower limbs (knee and ankle), followed by concussions (head) [18, 19]. In particular, the high rate of concussions during training and matches is a constant concern in American football $[1,13]$.

Although retrospective studies have already evidenced the main injuries in American football, the origins or associated factors are not totally clear. It is known that sports injuries can be derived from 2 main categories: intrinsic and extrinsic risk factors [20]. Intrinsic factors are those related to age, sex, physical condition, motor development, eating and psychological factors. Extrinsic risk factors, in turn, are associated with the technical specificity of each modality, type of equipment used, organization of training and competition, loads of training and competition, and climatic conditions [21]. Serrano et al. [22] highlight that the characteristics of the training, such as inadequate physical preparation, may be one of the main reasons for the injury incidence in team sports. However, there is little evidence in the literature concerning factors associated with injury prevalence in American football, especially regarding the characteristics of training.

The information about aetiology and prevalence of injury, as well as associated factors may help professionals to understand the origin of injuries and to develop strategies or mechanisms of prevention while aiming to maintain the physical and psychological integrity of the athletes. Reference to investigations in this modality is not common in amateur football players, as observed in Brazil. These teams usually have a limited number of athletes, which can increase the exposure to injuries, and the extended league calendar in Brazil when compared with Europe, Asia, and North America leagues could lead to injuries with specific origins and mechanisms.
Given that, the purpose of the study was to identify the injury prevalence and its association with factors related to the characteristics of physical training in American football players from Brazil. We hypothesized that there would be a high prevalence of injuries, mainly in the lower limbs, by contact mechanism; American football injuries would be associated with training characteristics.

\section{Material and methods}

\section{Participants}

The population of this study was composed of amateur American football players from the 6 teams that participated in the state championship of Santa Catarina, Brazil, in 2016, totalling 450 athletes. The questionnaire was answered by 140 athletes ( $31.1 \%$ of the population). The sample size was calculated with the assumption of an error of $5 \%$ and confidence interval of $90 \%$ [23]; thus, a minimum of 150 participants would be considered representative of the population. We were

Table 1. Training characteristics of the athletes

\begin{tabular}{lcc}
\cline { 2 - 3 } & $n$ & $\%$ \\
\hline $\begin{array}{l}\text { Playing time (years) } \\
<1\end{array}$ & 34 & 24.3 \\
$1-3$ & 51 & 36.4 \\
$>3$ & 55 & 39.3 \\
\hline Number of sessions per week & & \\
1 & 14 & 10.0 \\
$2-3$ & 95 & 67.9 \\
$>3$ & 31 & 22.1 \\
\hline
\end{tabular}

Participation in a conditioning program

$\begin{array}{lrr}\text { Yes } & 127 & 90.7 \\ \text { No } & 13 & 9.3\end{array}$

Type (modality)

of the conditioning program

Resistance training $\quad 115 \quad 66.5$

Functional training $\quad 39 \quad 22.5$

$\begin{array}{lll}\text { Other } & 6 & 3.5\end{array}$

Number of training sessions

of the conditioning program

$\begin{array}{lrr}1 & 4 & 2.9 \\ 2-3 & 42 & 30.0 \\ >3 & 81 & 57.9\end{array}$

Note: Some athletes performed more than one type of conditioning program; that is why the $n$ in this category exceeds the total $n$ value. 
unable to achieve the calculated sample size, which can be regarded as a limitation of the study.

The participants presented the following characteristics: age, $25.3 \pm 4.6$ years; body mass, $92.9 \pm$ $19.2 \mathrm{~kg}$; height, $180.5 \pm 7.5 \mathrm{~cm}$. The training characteristics of the athletes are displayed in Table 1. All players officially represented a state team.

\section{Instruments and procedures of data collection}

We used an online questionnaire created in the Google Forms platform to evaluate the prevalence of injuries, that is the proportion of athletes who had an injury during a period [24] (in the study, we considered 1 year). The questionnaire was composed of multiple choice questions, divided in 3 sections: (a) informed consent form; (b) athlete and training characteristics; (c) identification of injuries in the previous 12 months by: type (joint, muscle, bone, etc.), body segment injured, origin of the injury (matches or training), mechanism of the injury (contact or non-contact), and time away from matches or training.

The definition of injury in the study was adapted from another paper [18] and it referred to any injury resulting from playing American football (match or training) that required medical attention (of a physical therapist or medical doctor), which might or not result in time away.

The clarity of the questionnaire items was tested by a part of the study sample $(n=11)$ and determined in a nominal scale of $0-10$, in which 0 was considered totally unclear and 10 totally clear. The questions that obtained a minimum score of 8 (8.0) for clarity were approved and those which received some 'confused' and/or 'unclear' reactions were reviewed and modified. Afterwards, the validity of the questions was verified by 3 physical education and physical therapy professors with the use of a nominal scale of $0-10$. The questions that obtained a minimum score of 8 (8.0) were considered valid and those below this score were reviewed and modified [25].

An e-mail was sent to the Santa Catarina Federation of American Football (FCFA, Federação Catarinense de Futebol Americano) and to all team directors with an invitation to participate in the study. After receiving the subjects' consents, we explained all study procedures to them. The questionnaire was administered by electronic means. Each participant answered the questionnaire by himself, without the help of an interviewer.

\section{Statistical analysis}

Descriptive statistics (measures of frequency, central tendency, and variability) were used to show the injury prevalence among the athletes. Logistic regression analysis was performed to test a possible association between the variables (prevalence of injuries vs. training characteristics). The results were presented in odds ratio and the respective 95\% confidence intervals. A $t$-test for independent samples was applied for comparison of injury occurrence (match vs. training) and injury mechanism (contact vs. non-contact). The data were tabulated in the Microsoft Excel software and in the SPSS 18.0 software for inferential analysis. Statistical significance was set as $p<0.05$.

\section{Ethical approval}

The research related to human use has been complied with all the relevant national regulations and institutional policies, has followed the tenets of the Declaration of Helsinki, and has been approved by the ethics committee of the local university (protocol number: CAAE 55083316.6.0000.5357).

\section{Informed consent}

Informed consent has been obtained from all individuals included in this study.

\section{Results}

The injury prevalence found in the present study was $74.3 \%(n=104)$. The most frequent injured body parts were shoulders (14.3\%), followed by knees (13.0\%) and hand/fingers (12.7\%) (Figure 1). Athletes who

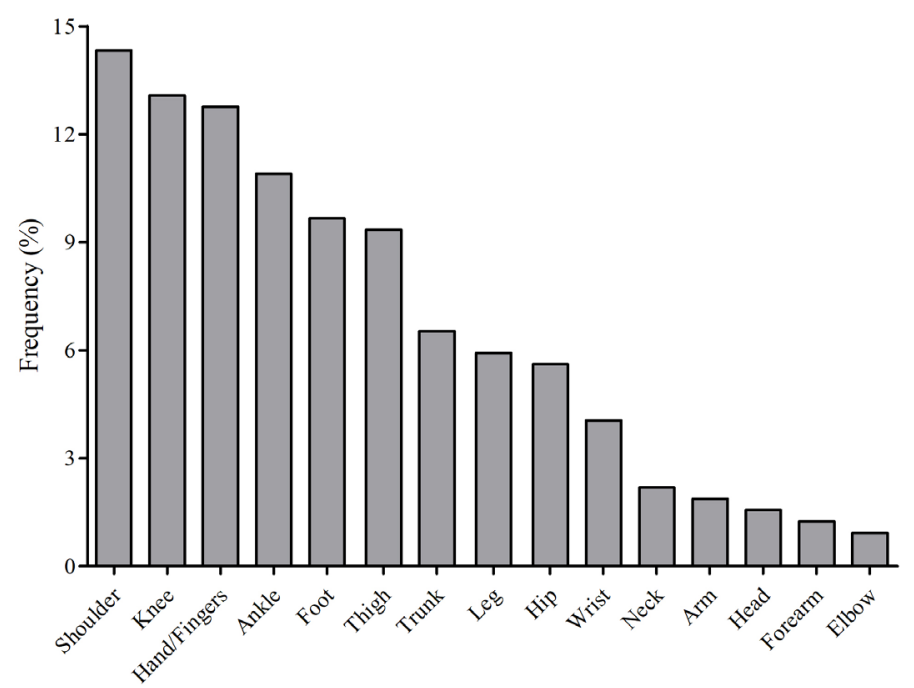

Figure 1. Prevalence of injuries regarding body parts (segments and joints) 
F.E. Costa, J. Dal Pupo, J. Barth, E.S. Bezerra, A.F. Salvador, Injury prevalence in American football

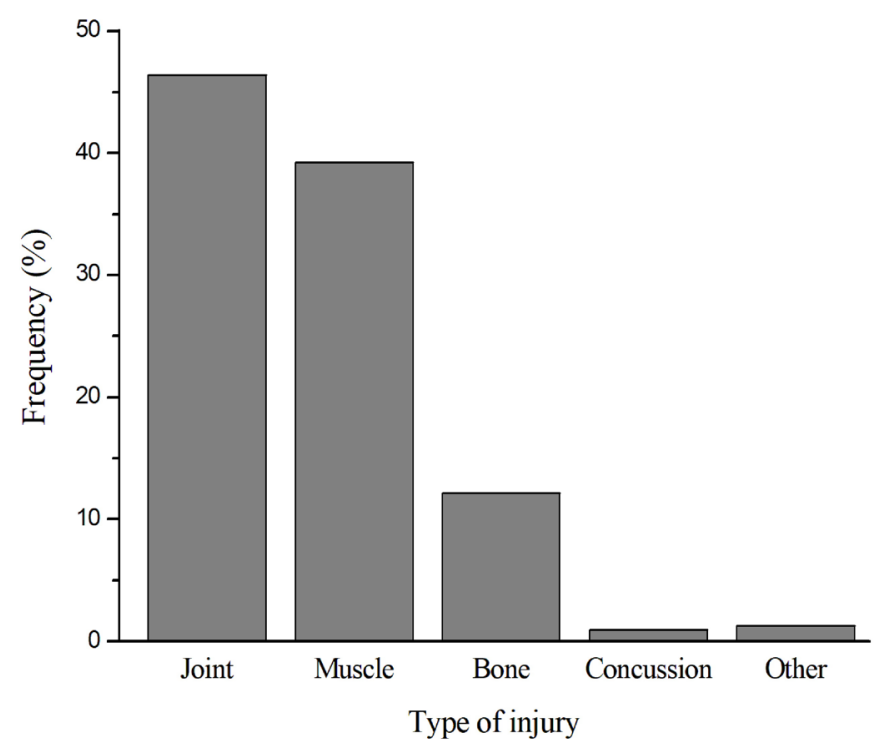

Figure 2. Injury prevalence with reference to type

answered 'yes' for injury occurrence could indicate more than one injury; so, the results in Figure 1 refer to the total number of injuries $(n=321)$. Regarding the type of injuries (Figure 2), it was noted that injuries related to joints and muscles were the most frequent.

Injury mechanisms (contact or non-contact with other players) and origin (match or training) are shown in Figure 3. It was observed that most injuries occurred through direct contact compared with noncontact (64.8\% and 35.2\%, respectively; $p<0.001$ ). Also, a higher frequency of injuries referred to training than to matches $(56.4 \%$ and $43.6 \%$, respectively; $p=0.01$ ).

It was determined that $29.9 \%$ of injuries did not cause any absence of the athlete in training or matches. The injuries that resulted in a time away of 1-7 days or 7-21 days had a frequency of 24.3\% each, 21 days-3 months had a frequency of $12,7 \%$, and $8.7 \%$ of injuries were bound with more than 3 months of recovery time.

Analyses of the association between injury prevalence and training characteristics of the athletes were performed. No significant association was observed of injury prevalence with playing time $(p=0.16)$, num-

Table 2. Association between injury prevalence and participation in a conditioning program

\begin{tabular}{ccccr} 
& & \multicolumn{3}{c}{ Participation in a conditioning program } \\
\cline { 3 - 5 } & & Yes & No & \multicolumn{1}{c}{ Total } \\
\hline \multirow{2}{*}{ Injury } & Yes & $98(94 \%)$ & $6(6 \%)$ & $104(100 \%)$ \\
& No & $29(81 \%)$ & $7(19 \%)$ & $36(100 \%)$ \\
\hline \multirow{3}{*}{ Total } & $127(91 \%)$ & $13(9 \%)$ & $140(100 \%)$ \\
\hline
\end{tabular}

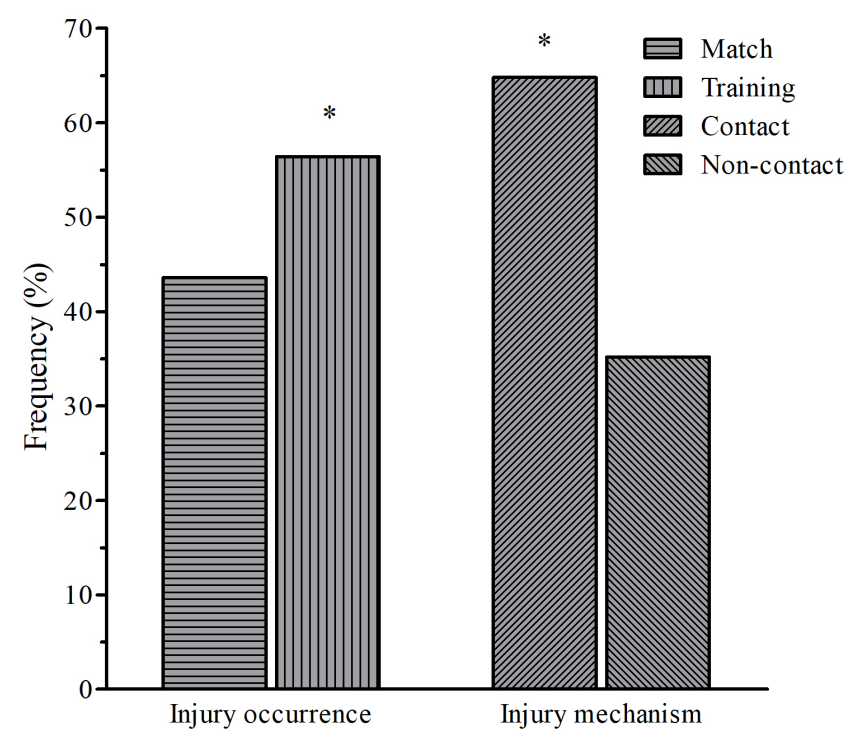

* Statistically significant differences between match and training and between contact and non-contact.

Figure 3. Injury prevalence regarding mechanism and origin

ber of training sessions per week $(p=0.68)$, or player position (offence or defence) ( $p=0.92)$. In turn, a statistically significant association was found between injury prevalence and participation in a conditioning program ( $p=0.01$ ) (Table 2 ), showing that most of the injuries occurred while athletes were engaged in a conditioning program. The odds ratio of having an injury in the case of athletes who took part in a conditioning program was 3.94 times higher (95\% CI, 1.23$12.66 ; p=0.02$ ) than for those who took no physical conditioning program. The type of physical conditioning (resistance training, functional training, or others) had no impact on the prevalence of injuries $(p=0.23)$.

\section{Discussion}

The purpose of the study was to analyse the injury prevalence in American football players of the Santa Catarina state in Brazil. It is important to mention that this is the first study to investigate the prevalence of injuries in American football in Brazil - becoming important because of the growing popularity of this sport in the country in recent years. High injury prevalence $(74.3 \%)$ was observed, corroborating the results of international studies referring to college American football players [7, 18, 19]. The findings of the present study showed that the most frequently injured body parts were shoulders, knees, and hand/fingers. The majority of the injuries occurred through direct contact between players. Also, injuries during training were more frequent than those during matches, but 
more than a quarter of them did not result in the absence of players. The only association of injury prevalence with training characteristics related to participation in a conditioning program.

In relation to the injured body parts, as presented in Figure 1, we can observe a higher prevalence in the lower limbs (54.4\%) compared with the upper limbs $(35.2 \%)$ and trunk, neck and head (10.2\%). Similar results were obtained in other studies, with the prevalence ranging from $46.9 \%$ to $60.2 \%$ in the lower limbs [17-19], and the knee among the 3 most frequently injured body parts in American football players [7, 10, 17-19]. These findings indicate that, although players carry and throw the ball with their hands, the lower limbs are highly exploited and therefore exposed to injuries. Knee injuries may be associated with several intrinsic or extrinsic factors, but the agonist/antagonist muscle imbalance around the knee has been identified as a major cause [26, 27]. In addition, some cases of knee twisting are caused by stepping on irregular surfaces in fields, commonly observed in Brazilian teams' facilities. Regarding the hand/fingers, the present study revealed a higher injury prevalence compared with previous studies [7, 12, 17-19]. It is important to remark that almost half of the injuries in the hand/fingers did not require a player's absence in match or training, perhaps because it is possible to still play using some type of bracing or taping on this body part. In other studies [7, 12, 17-19], injuries that did not require time away from training or matches were not counted - as opposed to the present study.

The main types of reported injuries were those related to joints, followed by muscular injuries, as shown in Figure 2. As for muscular injuries, epidemiological studies have shown that in American football they mostly occur in the lower limbs, especially in hamstrings $[10,12,17]$. In our study, the prevalence of injuries was calculated specifically for the thigh segment, and the majority (80\%) originated from non-contact mechanisms, which suggests their muscular nature. The risk of hamstring injuries tends to be higher during maximum sprints performed in matches; a strong eccentric strength is then required in hamstrings to decelerate the free leg during the swing phase in preparation for ground contact [26]. Fatigue has been considered as a predisposing factor in these situations since half of all these injuries occurred in the last stages of a match, when the muscle capacity to generate force is reduced [28]. According to another study [29], decreased hamstring force lowers energy absorption capabilities and raises the potential for injury.
In American football, one type of injury that has been highly discussed over the years is concussion. A particular characteristic of this sport is that the head is highly exposed during plays. Surprisingly, in our study, only $0.93 \%$ of the total number of injuries were reported as concussion injuries - unlike in other studies, in which concussion frequency varies from $2 \%$ to $9.6 \%$ of all injuries [1, 10, 17, 18]. One aspect that may explain the low frequency of concussions in our study is the complexity in identifying this type of injury by the athletes or the lack of qualified staff to diagnose a concussion. It is worthwhile to mention that helmets give to the athlete a false feeling of protection, and the use of head as the first contact point during blocks and tackles increases, even if not permitted in the official rules of the match, which leads to a higher risk of injuries [11, 30, 31]. Some strategies can be developed to reduce the number of contacts that can cause head impacts during training, and, thereby, lower the risk of concussions [1]. For example, head impact exposure time is related to the coach education, which means that different types of training could help to reduce head impacts and thus the concussion rate [14].

Regarding the origin of the injury (match or training), a higher number of injuries were reported on training, which corroborates several studies [12, 17-19]. This result may be related to more exposure time to training than to matches. The guidelines of the National Collegiate Athletic Association (NCAA) in the United States limit the maximum frequency of training, but these guidelines are not applied in Brazil. To the contrary, it has been reported that long training and performing a lot of match simulations, mainly with technical-tactical characteristics, encourage an elevated number of tackles and blocks and, consequently, lead to increased injury exposure [19]. The majority of the injuries in the present study were caused by contact, as previously reported in other studies [12, 17-19]. With the consideration of the characteristics of American football, programs and strategies are developed by professionals to protect the players' health without losing effectiveness.

One important concern when an injury occurs is to know how long the athlete will be out of training. This directly influences the possibility of a player to participate in an official match. In this study, 29.9\% of the injuries did not stop the athletes from playing or practising. In other studies, it has been reported that $58.6 \%$ and $76 \%$ of injuries in school and college athletes, respectively, did not require time loss [9, 30]. These contrasting results may be explained by the fact that international teams have better support for their 
F.E. Costa, J. Dal Pupo, J. Barth, E.S. Bezerra, A.F. Salvador, Injury prevalence in American football

players, offering diagnosis, treatment, and strategies to maintain the ability to train, with the help of taping, bracing, and some other types of intensive treatment before and after training.

The second objective of the present study was to investigate the possible associations of the injury prevalence with the characteristics of the athletes' training. The only significant association found was between injury prevalence and participation in an individual conditioning program; in fact, most of the athletes (94\%) affected by an injury were engaged in some conditioning program. This result seems to be alarming, since it is expected that training could help to decrease the frequency of injuries. However, a possible explanation would be that the well physically trained athletes present higher conditioning levels (i.e., they are faster and stronger), which leads to more collision forces and can increase the frequency of injuries [18]. Although the results of this study are not very encouraging in relation to an athlete joining a conditioning program, it is important to emphasize that a conditioning program is primordial to an athlete who aims at success in sport.

Finally, some practical applications arising from our main findings may be mentioned in order to help professionals to develop strategies or mechanisms of prevention while aiming to maintain the physical and psychological integrity of the athletes. Considering the high prevalence of injuries in American football, we recommend for coaches and trainers to monitor the total volume of training and participation in matches for the purpose of reducing injury exposure. In addition, as we observed a high prevalence of joint and muscle injuries, it should be advised to perform specific proprioceptive training focused on joint stabilization (mainly in the shoulder and knee).

The present study had some limitations that should be mentioned. A main one refers to the fact that each player filled in his own survey. In ideal conditions, medical staff or organization should register the injury characteristics. However, Brazilian teams do not have a professional structure, such as that of the National Football League or NCAA. Besides, the number of matches and trainings or the participation time of each player during a 12-month period were not determined, which made it impossible to create injury rates per hour or per athlete-exposure.

\section{Conclusions}

American football players in the Santa Catarina state are affected by a high injury prevalence, with the shoulder and knee joints being the most frequently injured body parts, while the main types of reported injuries were joint-related followed by muscular. These injuries mainly originated from the mechanism of direct contact between players, predominantly in training. The training characteristics, in general, did not seem to be associated with injury prevalence, even though, curiously, the only significant association proved that players engaged in a conditioning program faced a higher injury prevalence - possibly because of a greater exposure (i.e., playing more frequently).

\section{Disclosure statement}

No author has any financial interest or received any financial benefit from this research.

\section{Conflict of interest}

The authors state no conflict of interest.

\section{References}

1. Dompier TP, Kerr ZY, Marshall SW, Hainline B, Snook EM, Hayden R, et al. Incidence of concussion during practice and games in youth, high school, and collegiate American football players. JAMA Pediatr. 2015;169(7):659-665; doi: 10.1001/jamapediatrics. 2015.0210 .

2. Araujo AGS, Oliveira PK, Bosso SLA. Assessment of the power of lower limbs of American football players based on the hop test [in Portuguese]. Cinergis. 2009; 10(1):23-28; doi: 10.17058/cinergis.v10i1.1106.

3. Rodrigues FXF, Costa NCG, Pedroso LC, Silva JA. American football in the soccer country: the case of Cuiabá Arsenal [in Portuguese]. Barbarói. 2014;41(2): 227-247; doi: 10.17058/barbaroi.v2i41.4784.

4. Hoffman JR. The applied physiology of American football. Int J Sports Physiol Perform. 2008;3(3):387-392; doi: $10.1123 /$ ijspp.3.3.387.

5. Hoffman JR. Physiological demands of American football. Sports Sci Exch. 2015;28(143):1-6.

6. Spencer M, Bishop D, Dawson B, Goodman C. Physiological and metabolic responses of repeated-sprint activities: specific to field-based team sports. Sports Med.2005;35(12):1025-1044; doi:10.2165/00007256 -200535120-00003.

7. Willigenburg NW, Borchers JR, Quincy R, Kaeding CC, Hewett TE. Comparison of injuries in American collegiate football and club rugby: a prospective cohort study. Am J Sports Med. 2016;44(3):753-760; doi: 10.1177/ 0363546515622389.

8. Casson IR, Viano DC, Powell JW, Pellman EJ. Twelve years of National Football League concussion data. Sports Health. 2010;2(6):471-483; doi: 10.1177/19417 38110383963.

9. Dompier TP, Powell JW, Barron MJ, Moore MT. Timeloss and non-time-loss injuries in youth football players. J Athl Train. 2007;42(3):395-402. 
10. Feeley BT, Kennelly S, Barnes RP, Muller MS, Kelly BT, Rodeo SA, et al. Epidemiology of National Football League training camp injuries from 1998 to 2007. Am J Sports Med. 2008;36(8):1597-1603; doi: 10.1177/0363546 508316021.

11. Hagel B, Meeuwisse W. Risk compensation: a "side effect” of sport injury prevention? Clin J Sport Med. 2004; 14(4):193-196; doi: 10.1097/00042752-20040700000001.

12. Kerr ZY, Simon JE, Grooms DR, Roos KG, Cohen RP, Dompier TP. Epidemiology of football injuries in the National Collegiate Athletic Association, 2004-2005 to 2008-2009. Am J Sports Med. 2016;4(9):232596711 6664500; doi: 10.1177/2325967116664500.

13. Kerr ZY, Zuckerman SL, Wasserman EB, Covassin T, Djoko A, Dompier TP. Concussion symptoms and return to play time in youth, high school, and college American football athletes. JAMA Pediatr. 2016;170(7):647654; doi: 10.1001/jamapediatrics.2016.0073.

14. Kerr ZY, Yeargin SW, Valovich McLeod TC, Mensch J, Hayden R, Dompier TP. Comprehensive coach education reduces head impact exposure in American youth football. Orthop J Sports Med. 2015;3(10):232596711 5610545; doi: 10.1177/2325967115610545.

15. Kerr ZY, Snook EM, Lynall RC, Dompier TP, Sales L, Parsons JT, et al. Concussion-related protocols and preparticipation assessments used for incoming studentathletes in National Collegiate Athletic Association member institutions. J Athl Train. 2015;50(11):11741181; doi: 10.4085/1062-6050-50.11.11.

16. Powell JW, Dompier TP. Analysis of injury rates and treatment patterns for time-loss and non-time-loss injuries among collegiate student-athletes. J Athl Train. 2004;39(1):56-70.

17. Shankar PR, Fields SK, Collins CL, Dick RW, Comstock RD. Epidemiology of high school and collegiate football injuries in the United States, 2005-2006. Am J Sports Med. 2007;35(8):1295-1303; doi: 10.1177/ 0363546507299745.

18. Dick R, Ferrara MS, Agel J, Courson R, Marshall SW, Hanley MJ, et al. Descriptive epidemiology of collegiate men's football injuries: National Collegiate Athletic Association Injury Surveillance System, 1988-1989 through 2003-2004. J Athl Train. 2007;42(2):221-233.

19. Iguchi J, Yamada Y, Kimura M, Fujisawa Y, Hojo T, Kuzuhara K, et al. Injuries in a Japanese Division I collegiate American football team: a 3-season prospective study. J Athl Train. 2013;48(6):818-825; doi: 10.4085/ 1062-6050-48.4.15.

20. Bahr R, Holme I. Risk factors for sports injuries - a methodological approach. Br J Sports Med. 2003;37(5):384392; doi: 10.1136/bjsm.37.5.384.

21. Dos Santos SG, Detanico D, Piucco T, Dal Pupo J, dos Reis DC. Injuries incidence in handball athletes. FIEP Bulletin. 2008;78(1):20-23.

22. Serrano JM, Shahidian S, Voser RC, Leite N. Incidence and injury risk factors in Portuguese futsal players. Rev
Bras Med Esporte. 2013;19(2):123-129; doi: 10.1590/ S1517-86922013000200011.

23. Silva Junior JN, Kons RL, Dellagrana RA, Detanico D. Injury prevalence in Brazilian jiu-jitsu athletes: comparison between different competitive levels. Rev Bras Cineantropom Desempenho Hum. 2018;20(3):280-289; doi: 10.5007/1980-0037.2018v20n3p280.

24. Knowles SB, Marshall SW, Guskiewicz KM. Issues in estimating risks and rates in sports injury research. J Athl Train. 2006;41(2):207-215.

25. Dos Santos SG, Detanico D, Graup S, dos Reis DC. Relation between posture changes, prevalence of injuries and impact magnitude on lower limbs as regards the handball athletes. Fit Perf J. 2007;6(6):388-393; doi: 10.3900/fpj.6.6.388.e.

26. Small K, McNaughton L, Greig M, Lovell R. The effects of multidirectional soccer-specific fatigue on markers of hamstring injury risk. J Sci Med Sport. 2010;13(1): 120-125; doi: 10.1016/j.jsams.2008.08.005.

27. Croisier JL, Forthomme B, Namurois MH, Vanderthommen M, Crielaard JM. Hamstring muscle strain recurrence and strength performance disorders. Am J Sports Med.2002;30(2):199-203; doi: 10.1177/03635465020 300020901.

28. Dal Pupo J, Detanico D, dos Santos SG. The fatigue effect of a simulated futsal match protocol on isokinetic knee torque production. Sports Biomech. 2014;13(4): 332-340; doi: 10.1080/14763141.2014.981202.

29. Garrett WE Jr. Muscle strain injuries. Am J Sports Med. 1996;24(6 Suppl.):S2-S8; doi: 10.1177/03635465960 2406S02.

30. Powell JW, Dompier TP. The role of the helmet in the prevention of traumatic brain injuries. Curr Sports Med Rep. 2004;3(1):20-24; doi: 10.1007/s11932-004-0041-x.

31. Swartz EE, Broglio SP, Cook SB, Cantu RC, Ferrara MS, Guskiewicz KM, et al. Early results of a helmetless-tackling intervention to decrease head impacts in football players. J Athl Train. 2015;50(12):1219-1222; doi: 10.4085/1062-6050-51.1.06. 